\title{
Chemoselective reduction of carbonyl groups of aromatic nitro carbonyl compounds to the corresponding nitroalcohols using thiourea dioxide
}

\author{
Shikha Sambher, ${ }^{\mathrm{a}, \mathrm{b}}$ Chinnappan Baskar, and Ranjit S. Dhillon**a \\ ${ }^{a}$ Department of Chemistry, Punjab Agricultural University, Ludhiana - 141004, Punjab, India \\ ${ }^{b}$ Department of Chemistry, Lovely Professional University, Phagwara - 144402, Punjab, India \\ E-mail:hillonr@rediffmail.com,baskarc@yahoo.com
}

\begin{abstract}
Aromatic nitroaldehydes and ketones were selectively reduced to the corresponding nitroalcohols by thiourea dioxide (TUDO) in aqueous alkali-ethanolic system in good to high yields. The optimized synthetic methodology is simple, convenient and highly chemoselective.
\end{abstract}

Keywords: Chemoselective reduction, nitroaldehydes and ketones, thiourea dioxide (TUDO), formamidinesulfinic acid (FSA)

\section{Introduction}

The selective transformation of one functional group in the presence of other similar reducible functionalities using non-hazardous chemicals in economically feasible and environmentally benign conditions is a formidable task for synthetic organic chemists. Selectivity (chemo-, regio-, stereo-) and atom economy have been the crucial points because they define the overall length of a series of reactions that constitutes a synthetic strategy. Chemoselective reduction provides an important method for functional group transformation in organic synthesis. A variety of reagents have been employed to achieve this transformations. ${ }^{1-7}$ Despite the fact that a plethora of reducing agents is available for this operation, new reagents, especially the catalytic versions, are still highly desirable. Thiourea dioxide is much less expensive and does not affect the environment.

Thiourea dioxide (TUDO) or formamidinesulfinic acid (FSA) - a commercially available reducing agent has vast applications for waste papers processing, ${ }^{8}$ wool bleaching, ${ }^{9}$ the reduction of ferredoxin, cyctochrome $\mathrm{C}$ and methaemoglobin. ${ }^{10}$ TUDO is also used for the reduction of organosulfur compounds (sulfylimines, sulfoxides, disulfides); ${ }^{11}$ for the synthesis of selenides and tellurides from the corresponding diselenides and ditellurides under phase transfer catalysis; ${ }^{12}$ and the deoxygenation of $\alpha, \beta$-epoxy ketones. ${ }^{13}$ 
Our research is mainly devoted to finding new procedures for chemoselective reduction of organic functionalities using inexpensive and green reagents. ${ }^{14-20}$ We report herein a simple and convenient procedure for chemoselective reduction of aromatic nitroaldehydes and ketones using TUDO-NaOH-EtOH at $90{ }^{\circ} \mathrm{C}$ to the corresponding nitroalcohols (Scheme 1).

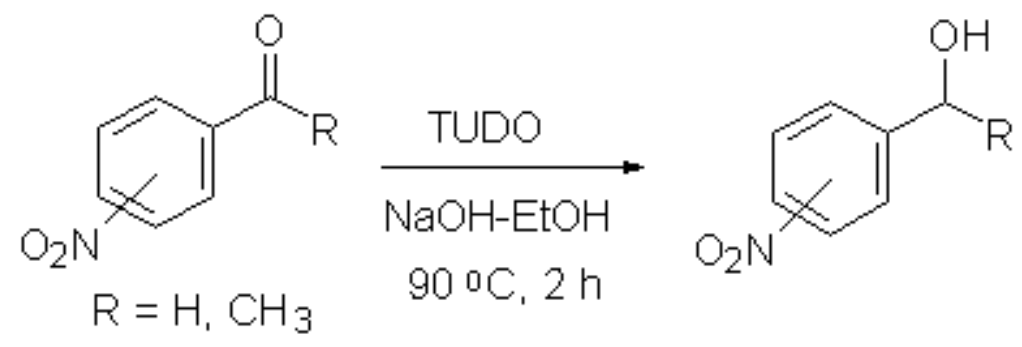

Scheme 1. Chemoselective reduction of aromatic nitrocarbonyls to the corresponding nitroalcohols with TUDO-NaOH-EtOH.

\section{Results and Discussion}

In the beginning of our research, we have found that the chemoselective reduction of $\mathrm{m}$ nitrobezaldehyde as a model compound with one equivalent of TUDO in aqueous alkaliethanolic system at $90^{\circ} \mathrm{C}$ for $2 \mathrm{~h}$ to give the corresponding $m$-nitrobenzylalcohol (Entry 1).

Next, we examined the same reaction condition for the chemoselective reduction of a variety of aromatic nitroaldehydes and ketones. The results are summarized in Table 1. In all the case of aromatic nitroaldehydes, the selective reduction proceeded at $90{ }^{\circ} \mathrm{C}$ for $2 \mathrm{~h}$ to give the corresponding nitroalcohols in good yields (Entry 1-3). The chemoselective reduction of carbonyl was perfect and nitroalcohols as the sole product besides nitro group as an intact material. On the other hand, the selective reduction of nitro-substituted aryl methyl ketones required a longer reaction time (6h) at $90{ }^{\circ} \mathrm{C}$ to afford the corresponding nitroalcohols in good yields (Entry 4 \& 5).

The chemoselective reduction of carbonyl compounds was further confirmed by spectroscopic analysis. IR data of product shows absence of a carbonyl band at $1700 \mathrm{~cm}^{-1}$. The absorption at $1526 \mathrm{~cm}^{-1}$ and $1345 \mathrm{~cm}^{-1}$ shows the presence of a nitro group indicating that reduction has occurred at the carbonyl moiety only. The appearance of an absorption band in the region $>3300 \mathrm{~cm}^{-1}$ shows the presence of an -OH group in the product. This was further confirmed by the presence of a deuterium exchangeable proton signal in the ${ }^{1}$ HNMRspectrum. This unique reactivity of TUDO-NaOH-EtOH system affords the possibilities for achieving selective reduction of carbonyl groups in the presence of other functional groups in complex molecules. 
Table 1. Chemoselective reduction of carbonyl moiety of nitrocarbonyls with TUDO at $90^{\circ} \mathrm{C}$

\begin{tabular}{lllll}
\hline Entry & Reactant & Product $^{\mathrm{a}}$ & Time (h) & Yield (\%) \\
\hline
\end{tabular}

1<smiles>O=Cc1cccc([N+](=O)[O-])c1</smiles>

2<smiles>O=Cc1ccccc1[N+](=O)[O-]</smiles>

3<smiles>O=Cc1ccc([N+](=O)[O-])cc1</smiles>

4<smiles>CC(=O)c1cccc([N+](=O)[O-])c1</smiles>

5<smiles>CC(=O)c1ccc([N+](=O)[O-])cc1</smiles><smiles>O=[N+]([O-])c1cccc(CO)c1</smiles>

2 80<smiles>O=[N+]([O-])c1ccccc1CO</smiles>

2 80 80 $\mathrm{O}_{2}$<smiles>CC(O)c1cccc([N+](=O)[O-])c1</smiles>

6 75

6 75

${ }^{\mathrm{a}}$ Products were characterized by comparison (m.p./b.p, TLC, IR, ${ }^{1} \mathrm{H}$ NMR \& Elemental analysis) with authentic samples. 


\section{Conclusions}

In conclusion, we have shown that TUDO-NaOH-EtOH system reduces selectively carbonyl groups of aromatic nitro aldehydes or ketones to the corresponding nitro alcohols. Excellent chemoselectivity, convenient procedure, mild reaction condition, good to high yields of the products and also easy work-up of the reaction mixture make this system as an attractive method and a synthetically useful addition to the present methodologies. We are currently focusing on the following topics: (i) Expansion of the concept of competitive selective reduction of carbonyls using TUDO and (ii) Development of green chemical transformation of organic functionalities. The initial results will be reported in due course.

\section{Experimental Section}

General Procedures. All reagents were purchased from Sigma-Aldrich and SD Fine and were used without further purification unless otherwise stated. Products were characterized by a comparison with authentic samples: m.p./b.p, mixed m.p. (wherever applicable), IR, and NMR. All yields refer to isolated pure products. TLC was applied for the purity determination of substrates, products, and reaction monitoring over silica gel glass plate.

General procedure for chemoselective reduction of aromatic nitroaldehydes/ketones with TUDO in aqueous alkali-ethanolic system

Aqueous $\mathrm{NaOH}(20 \mathrm{mmol})$ and solid thiourea dioxide (1.08 g, $10 \mathrm{mmol}$, in one lot) were added to Nitroaldehyde or nitroketone $(10 \mathrm{mmol})$ dissolved in ethanol $(30 \mathrm{~mL})$. The mixture was stirred for $2 \mathrm{~h}$ (for nitroaldehyde) or $6 \mathrm{~h}$ (for nitroketone) at $90{ }^{\circ} \mathrm{C}$, cooled to room temperature and ethanol was distilled off. The aqueous layer was extracted with $\mathrm{Et}_{2} \mathrm{O}(3 \times 25 \mathrm{~mL})$, and dried (anhyd. $\mathrm{Na}_{2} \mathrm{SO}_{4}$ ). The crude products were purified by column chromatography on silica gel using a solvent mixture (EtOAc:hexane) to get the corresponding pure nitroalcohol in $75-80 \%$ yield (Table 1).

Entry 1. ${ }^{1} \mathrm{H}$ NMR (CDCl,$\delta$ ppm): 2.95 (br, $1 \mathrm{H}$, exchangeable with $\left.\mathrm{D}_{2} \mathrm{O}\right) ; 4.79$ (s, 2H); 7.51 8.17 (m, 4H). IR (neat, $\mathrm{cm}^{-1}$ ): 3355, 3042, 2890, 1526, 1352, 1045, 800, 731. Anal. Calcd. for $\mathrm{C}_{7} \mathrm{H}_{7} \mathrm{O}_{3} \mathrm{~N}$ : C, 54.90; H, 4.58; O, 31.37; N, 9.15. Found: C, 54.93; H, 4.55; O, 31.36; N, 9.12.

Entry 2. ${ }^{1} \mathrm{H}$ NMR $\left(\mathrm{CDCl}_{3}, \delta \mathrm{ppm}\right): 3.06$ (br, $1 \mathrm{H}$, exchangeable with $\left.\mathrm{D}_{2} \mathrm{O}\right) ; 4.90$ (s, $2 \mathrm{H}$, $\mathrm{CH}_{2} \mathrm{OH}$ ); 7.45 -8.04 (m, 4H). IR (neat, $\mathrm{cm}^{-1}$ ): 3312, 2934, 2849, 1526, 1518, 1345, 1055, 1036, 790, 725. Anal. Calcd. for $\mathrm{C}_{7} \mathrm{H}_{7} \mathrm{O}_{3} \mathrm{~N}$ : C, 54.90; H, 4.58; O, 31.37; N, 9.15. Found: C, 54.93; H, 4.55; O, 31.36; N, 9.12.

Entry 3. ${ }^{1} \mathrm{H}$ NMR (CDCl $3, \delta$ ppm): 2.40 (br, $1 \mathrm{H}$, exchangeable with $\mathrm{D}_{2} \mathrm{O}$ ); 4.81 (s, 2H); 7.52 8.17 (m, 4H). IR (neat, $\mathrm{cm}^{-1}$ ): 3621, 3115, 2925, 2867, 1511, 1345, 1060, 860, 735. Anal. Calcd. for $\mathrm{C}_{7} \mathrm{H}_{7} \mathrm{O}_{3} \mathrm{~N}$ : C, 54.90; H, 4.58; O, 31.37; N, 9.15. Found: C, 54.93; H, 4.55; O, 31.36; N, 9.12. 
Entry 4. ${ }^{1} \mathrm{H}$ NMR (CDCl $3, \delta$ ppm): 1.45 (d, J=6Hz, 3H); 3.95 (br, $1 \mathrm{H}$, exchangeable with $\mathrm{D}_{2} \mathrm{O}$; 4.68 (q, J=11Hz, 1H); 7.60-8.21 (m, 4H). IR (neat, $\mathrm{cm}^{-1}$ ): 3350, 2970, 2939, 1585, 1565, 1490, 1365, 1255, 890, 810, 745. Anal. Calcd. for $\mathrm{C}_{8} \mathrm{H}_{9} \mathrm{O}_{3} \mathrm{~N}$ : C, 57.49; H, 5.39; O, 28.74; N, 8.38. Found: C, 57.45; H, 5.33; O, 28.75; N, 8.37.

Entry 5. ${ }^{1} \mathrm{H}$ NMR $\left(\mathrm{CDCl}_{3}, \delta \mathrm{ppm}\right): 1.39(\mathrm{~d}, \mathrm{~J}=6 \mathrm{~Hz}, 3 \mathrm{H}) ; 3.75$ (br, $1 \mathrm{H}$, exchangeable with $\mathrm{D}_{2} \mathrm{O}$ ); 4.65 (q, J=11Hz, 1H); 7.60 (d, J=7Hz, 2H); 8.20 (d, J=7Hz, 2H). IR (neat, $\mathrm{cm}^{-1}$ ): 3365, 2975,2940, 1595, 1525, 1345, 1200, 1120, 1025, 900, 820, 780, 720. Anal. Calcd. for $\mathrm{C}_{8} \mathrm{H}_{9} \mathrm{O}_{3} \mathrm{~N}$ : C, 57.49; H, 5.39; O, 28.74; N, 8.38. Found: C, 57.45; H, 5.33; O, 28.75; N, 8.37.

\section{Acknowledgements}

Financial support from UGC, New Delhi is gratefully acknowledged.

\section{References}

1. Dhillon, R. S. Hydroboration and Organic Synthesis: 9-Borabicyclo [3.3.1]nonan (9-BBN); Springer: Germany, 2007.

2. Lee, S. H.; Nam, M. H.; Cho, M. Y. Yoo, B. W.; Rhee, H. J.; Yoon, C. M. Synth. Commun. 2006, 36, 2469.

3. Halimjani, A. Z.; Saidi, M. R. Synth. Commun. 2005, 35, 2271.

4. Zeynizadeh, B.; Yahyaei, S. Bull. Korean Chem. Soc. 2003, 24, 1664.

5. Uysal, B.; Buyuktas, B. S. Arkivoc 2007, (xiv), 134.

6. Chandrasekhar, S.; Prakash, S. J.; Rao, C. L. J. Org. Chem. 2006, 71, 2196.

7. Lee, D.; Kim, D.; Yun, J. Angew. Chem. Int. Ed. 2006, 45, 2785.

8. Makarov, S. V. Russ. Chem. Rev. 2001, 70, 885.

9. Daneault, C.; Leduc, C. Cellul. Chem. Technol. 1994, 28, 205.

10. Gacen, J.; Cegarra, J. J. Soc. Dyers Colourists 1991, 107, 138.

11. Shashova, V. E. Biochemistry 1964, 3, 1719.

12. Drabowicz, J.; Mikolajczyk, M. Synthesis 1978, 542.

13. Lang, E. S; Comasseto, J. V. Synth. Commun. 1989, 19, 239.

14. Samher, S.; Baskar, C.; Dhillon, R. S. Synth. Commun. 2008, 38, 2150.

15. Singh, J.; Kad, G. L.; Sharma, M.; Dhillon, R. S. Synth. Commun. 1998, 28, 2253.

16. Dhillon, R. S.; Singh, R. P.; Kaur, D. Tetrahedron Lett. 1995, 36, 1107.

17. Dhillon, R. S.; Nayyar, K. Tetrahedron Lett. 1992, 33, 6015.

18. Gautam, V. K.; Singh, J.; Dhillon, R. S. J. Org. Chem. 1988, 53, 187.

19. Mankatala, R.; Dhillon, R. S.; Chhbra, B. R. Indian J. Chem. 2006, 45B, 1591.

20. Jolly, D. P.; Arpan, S.; Chabbra, B. R.; Dhillon, R. S. Pesticide Research Journal 2005, 17, 1. 